\section{Responsible Research and Innovation - Perspectives and Challenges}

\author{
Report on the S.NET 6th Annual Meeting: \\ "Better Technologies with No Regret?"
}

Karlsruhe, Germany, September 21-24, 2014

\section{by Antonina Khodzhaeva, Martin Sand, Maria João Maia, Silvia Woll, Gabriel Velloso, and Daniel Frank, ITAS}

\section{Addressing Normativity}

New technologies can potentially provide solutions to old and new problems, but at the same time they are associated with controversies, uncertainties and risk. Assessment of emerging technologies regarding possible consequences is therefore very important for achieving "better technology (in a better society)" (Schot/Rip 1997, p. 256). The field of technology assessment (TA) is already known for providing evaluation of intended and non-intended impacts of new technologies, and various approaches to TA have already been developed to serve this purpose. However, in recent years the concept of Responsible Research and Innovation (RRI) has become very popular, in particular in the European policy context. It is suggested to represent the standard of European technology governance. The concept of RRI, largely based on the TA tradition, has qualified as an umbrella term, incorporating not only TA, but also Science, Technology and Society (STS) studies (cf. Grunwald 2011). Thus, the emergence of this concept indicated a turn from the debate on managing risk to managing the whole innovation process, a development also reflected in the program of the 6th Annual Meeting of the Society for the Study of Nanoscience and Emerging Technologies (S.NET). The authors of the report of the first Annual Meeting of the S.NET in 2009 questioned, “(...) whether the S.NET's attempts to bridge the gaps between different disciplines and occupational fields will achieve sustained success" (Coenen/Yang 2010, p. 205). It is now for the sixth time that the Society brings together scholars and practitioners from the natural scienc- es, social sciences and humanities as well as from various scientifically interested societal groups. This year's Annual Meeting of the S.NET was held under the striking title: "Better Technologies with No Regret?" Regret is usually understood as a moral sentiment triggered by conscience. It refers to actions and decisions in the past and is associated with feelings of discomfort. Regret occurs when things went wrong and it is too late to revise them. It is symptomatic that the Society has picked this title. It refers to rational anticipatory planning and the individual's relation to faulty actions. Regret is - just as responsibility and consternation - not transferable, and this applies both to actions in private and public life. Thus, the motto underscored the aim of the conference, namely to critically assess a broad spectrum of emerging technologies and analyze the role of policy makers and stakeholders in this process. It also expressed the normative dimension of RRI which, with all its intrinsic difficulties, was at the forefront of the conference. The meeting took place at the Institute for Technology Assessment and Systems Analysis (ITAS) in Karlsruhe.

\section{Discussion of Sessions}

With more than 20 sessions and several workshops as well as a film screening, the conference covered a wide spectrum of topics, which will be summarized in the following.

\section{ELSI Aspects of New and Emerging Technologies}

Technical innovation cannot be shaped only by economic and commercial interests. Broad ethical, legal and societal implications (ELSI) should also be considered in the complex process of innovation. In this context, a broad range of new and emerging technologies - from epigenetics (Stefanie B. Seitz), to emerging body technosciences (Bárbara Nascimento Duarte), brain-computer interfaces (Gabriel T. Velloso), personalized cancer medicine (Anne Blanchard), and synthetic biology (Luciano Kay and Jennifer Woolley; Celso Gomes) - were discussed in various sessions. For the first time in the history of S.NET conferences, a session was dedicated to the emerging 
and vast field of robotics. Florian Kreuchauff and Ingrid Ott presented the case of service robotics and the problem of effective policy recommendations resulting from gaps in definition and classification of "service robots". Maria João Maia and Bettina-Johanna Krings presented the specific case of surgical robots and the consequences of introducing these teleoperated systems in an operating room theater, namely in terms of work organization, qualification of human resources, and new man-machine interfaces. They reflected on the shifts medicine is facing on different levels with the introduction of such robots, highlighting the need to deepen the knowledge of such consequences and the role technology assessment can play in this quest. The presentation by Kjetil Rommetveit, Kristrún Gunnarsdottir, Niels van Dijk, and Martijntje Smits addressed the ways of defining a robotics agenda, which meets the RRI criteria and would be beneficial for society.

\section{Responsible Research and Innovation}

In the recent years, the concept of RRI has become very prominent, leading to a shift in science, technology and innovation policy in Europe. However, in order to apply this concept in practice, many conceptual challenges must be overcome. Several papers address the conceptualization of terms like "responsibility" and "responsible", which are rather vague, and lead to the assumption that previous research was not responsible (Stephan Lingner; Tsjalling Swierstra). Zoë Robaey highlighted the responsibility of the owners - "the ones purposely carrying out an action with a technology" - for hazards of Genetically Modified Organisms (GMOs). Robaey argued that the relationship between the concept of responsibility and the concept of ownership had not yet been considered appropriately. Regulatory tools are necessary in order to incorporate "responsibilization" into the governance of RRI (Bärbel Dorbeck-Jung). Viewing innovation as a non-linear, complex process can also have implications for the RRI concept (Boenink et al.). Stevienna de Saille approached the inclusion of the "unruly" public, such as activists, bloggers, independent researchers, etc., in R(R)I by analyzing their perception and understanding of responsible innovation and the differences be- tween the questions they raise and the ones raised by "traditional" stakeholders. Some papers presented at the conference addressed the practical implementation of the concept in such projects as NanoNextNL in the Netherlands (Bart Walhout), where Risk Analysis and Technology Assessment (RATA) was part of the research agenda. One consequence of implementing RRI is the involvement of researchers from the social sciences and humanities at early stages of research and in the assessment of emerging technologies. The paper by Susan Molyneux-Hodgson investigated the experiences of a sociologist working with scientists and engineers in a synthetic biology research project. In her contribution, she explored how the notions of responsibility were approached in this context. Rob Lubberink presented the preliminary ideas of his $\mathrm{PhD}$ project, in which he wants to challenge RRI from an economic perspective.

\section{Participation, Stakeholders}

Technology and innovation governance is becoming more democratic and open. Engaging a wide range of stakeholders in processes of responsible research and development of technologies, however, is not always easy. Differences among stakeholders can limit their ability to cooperate and form partnerships. Vincent Blok conceptualizes participation and partnerships by employing Emmanuel Levinas's perspective. The role of non-governmental organizations (NGOs) in the governance of new technologies is also changing, as demonstrated in the case of nanomaterials in the context of occupational health and safety (OHS) (Aline Reichow and Diana M. Bowman). Mitsuru Kudo presented a model of stakeholder engagement in science, technology and innovation (STI) policy topics in Japan based on public dialogue. Tom Wakeford in the session on GMOs addressed the role of non-scientific knowledge in public debates on food systems.

\section{Acceptance}

As long as a technology is not accepted, its potential benefits cannot be reaped, and there seems to be a gap between the acceptance by professionals 
and the acceptance by laypeople. The results of three medical studies show that technoscientific methods and applications are not uncritically taken as being of benefit in society. The acceptance of nanotechnology and cognitive enhancement in a medical context depends on factors such as the fear of the disease to be treated, the person's background as a patient or a healthcare professional, and the intention of the treatment. In their study, Marie-Sol Poirier, Vanessa Chenel, Johane Patenaude, and Patrick Boissy pointed out that acceptance can be defined in two ways: individual acceptance (intention of use) and social acceptance (what is desirable for society). Focusing on the results of the study, healthcare professionals are less in favor of the treatment based on carbon nanotubes (CNTs) in regard to its benefits for society. On the contrary, patients were favorable for the use of the treatment in terms of individual, as well as social acceptance. The study also demonstrated the relationship between purpose and context of use: respondents felt more comfortable using carbon-based nanocarriers to treat lung cancer than to treat influenza. Laura Y. Cabrera, Nicholas S. Fitz, and Peter B. Reiner pointed out in their presentation that participants rather agreed with a close friend using an enhancement pill if the intervention was described as ETN (enhancing to the norm) than when described as EAN (enhancing above the norm). Cabrera et al. made clear "that people are sensitive to variations of enhancement, and as such, if we are to have a more coherent ethics of enhancement, we have a social responsibility to explore further how these differences affect public attitudes towards enhancement".

\section{Visionary Technoscientific Practices, Futures and Imaginaries}

In recent years, an increasing number of publications have dealt with the visionary aspects of new and emerging technologies. Building on the works in Leitbild assessment on the one side and the Sociology of Expectations on the other side, those studies tried to explain the impact of visions on technological development. Providing a clear differentiation between such concepts as visions, imaginaries and meanings of scenarios remains a great challenge for the community. Imagination and responsibility for visionary practices, addressed by Arianna Ferrari and Laura Y. Cabre$\mathrm{ra}$, were not further discussed at the conference. This might deserve more attention at upcoming S.NET conferences. Besides visions, ideas, and ambitions - topics that have always been in the focus of the S.NET community -, imagining futuristic scenarios is a crucial element in the history and development of science. Fictional narratives have often inspired scientific approaches, and the way people imagine processes can initiate changes in science and research. Rasmus T. Slaattelid and Alexei Grinbaum used historic narratives to explain the mnemonic function of images (Slaattelid) and to emphasize the meaning of scientists' responsibilities and their limitations (Grinbaum). Zach Horton reflected on the question, whether one can look at the nanotech as an ecosystem by examining the debate between Richard Smalley and K. Eric Drexler. Michael G. Bennett's talk emphasized the importance of future-oriented approaches such as the assessment of possible futures and deployment of future figures and pointed out the possible benefits of future-oriented studies for legal practice and research.

\section{Workshops and Film Screening}

The conference included several workshops on Biohacking/DIY Biology, Life Cycle Assessment, and RRI. A group of DIY biologists (Rüdiger Trojok, Malthe Borch, Nora Vaage, Ana Delgado) hosted a hands-on workshop on biohacking. The idea of the workshop and subsequent discussion session was to explore the crisis of antibiotics resistance and how to "hack" our way out of it. The workshop offered a unique opportunity to engage with DIY biology and biohacking activities. It also made a valuable contribution to understanding the role of the RRI concept from a citizen science perspective. It became clear from the discussions that as science and innovation become more open source and open access, challenging issues and questions arise, which should be further addressed. The "Advancing Life Cycle Assessment for RRI" workshop was organized by Marcel Weil, Rider Foley, and Ben Wender. The participants were divided in groups and had to work on four different themes: (1) Values in 
Environmental LCA; (2) Data, Gaps, Assumptions, and Future Research Directions; (3) Filling the Toolbox; (4) Integrating Disparate Data to Inform Decisions. The activities always concluded with a brief discussion and summary. Christoph Schneider and Julia Hahn organized a very vivid and participative workshop in cooperation with FabLab Karlsruhe on "Hacking Responsible Innovation". Doorbells and assumptions made prior to their installation at a house entrance served as an example. Framing the problem (e.g. when different stakeholders are involved, such as children, disabled or blind persons) and coming up with solutions were some of the tasks the different groups had to work on, keeping in mind responsibility in the innovation process. Very interesting workshops allowed for different perspectives to be discussed. On the last day, several chapters of the film "Swerve" (directed by Zach Horton) were screened. The story of this film is set in the future, where reality merges with the virtual world in a nano-contaminated zone. The film screening was one of the highlights of the S.NET conference. Film is another medium that can help reflect on the implications of new technologies.

\section{Outlook}

The S.NET conference came up with a couple of refreshing formats such as a Biohacking workshop, a Film Screening Session with the director, and interactive workshops with members of FabLab Karlsruhe. The international and interdisciplinary community participating in the lively discussions during the conference opened up fruitful perspectives and interesting questions about new and emerging technologies. Both discussions and presentations maintained high quality throughout. At upcoming S.NET conferences, the economic perspective on RRI should receive increased attention. Innovation from an economic perspective has, with a few exceptions (e.g. Rob Lubberink), been neglected. Unfortunately, the feeling that the engineering perspective developed by the participants of the Life Cycle Assessment workshop was somehow separated from the rest of the conference did not vanish. Here is room for improvement. The rather untypical perspectives developed in the keynotes of
Andy Stirling and Sarah Davies inspired the participants to think innovation processes and technological development from completely different angles. While both presenters had proposed to think of innovation processes without any form of top-down normative approach or highly structured governance, the common challenges and dilemmas soon reappeared in the subsequent discussions. Supposing that innovation processes are to be described in the absence of governance, how can we then meet the requirements of RRI? If TA is supposed to give advice on the "right" impacts of emerging technologies and participatory research, and to develop a framework for stakeholder and public involvement in the process of shaping these technologies, how can this be accomplished with reference to a rather deterministic picture of innovation? Between action, reaction and pro-action, the right attitude towards new and emerging technologies is still too be found. This remains the challenge also for the upcoming conferences of the Society. The next S.NET conference should take place in October 2015 in Montreal. We are looking forward to it.

\section{References}

Coenen, C.; Yang, M., 2010: S.NET: A (Post-) Academic Society for the Study of Emerging Technosciences: Report on the first S.NET Conference, Seattle 2009. In: Fiedeler, U.; Coenen, C.; Davies, S.R. et al. (eds.): Understanding Nanotechnology: Philosophy, Policy and Publics. Heidelberg, pp. 199-209

Grunwald, A., 2011: Responsible Innovation: Bringing Together Technology Assessment, Applied Ethics, and STS Research; http://www.itas.kit.edu/ pub/v/2011/grun11c.pdf (download 26.1.15)

Schot, J.; Rip, A., 1997: The Past and the Future of Constructive Technology Assessment. In: Technological Forecasting and Social Change 54/2-3 (1997), pp. 251-268 